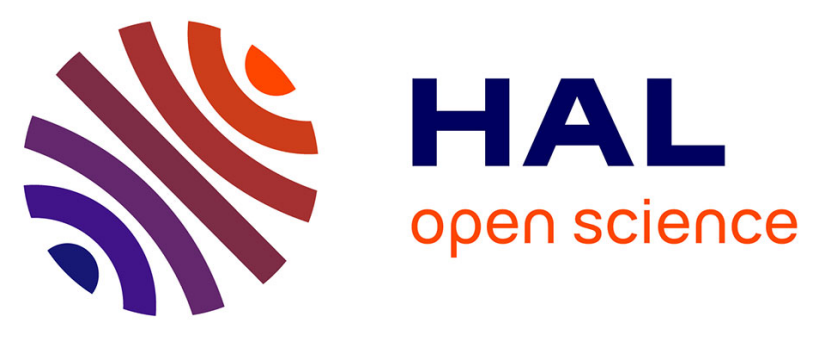

\title{
Gradient or statistical copolymers by batch nitroxide mediated polymerization: effect of styrene/methyl acrylate feed
}

Khaled Karaky, Eve Péré, Claude Pouchan, Hélène Garay, Abdel Khoukh, Jeanne François, Jacques Desbrieres, Laurent Billon

\section{To cite this version:}

Khaled Karaky, Eve Péré, Claude Pouchan, Hélène Garay, Abdel Khoukh, et al.. Gradient or statistical copolymers by batch nitroxide mediated polymerization: effect of styrene/methyl acrylate feed. New Journal of Chemistry, 2006, 30, pp.698-705. 10.1039/B515879F . hal-00069056

\section{HAL Id: hal-00069056 https://hal.science/hal-00069056}

Submitted on 1 Jun 2021

HAL is a multi-disciplinary open access archive for the deposit and dissemination of scientific research documents, whether they are published or not. The documents may come from teaching and research institutions in France or abroad, or from public or private research centers.
L'archive ouverte pluridisciplinaire HAL, est destinée au dépôt et à la diffusion de documents scientifiques de niveau recherche, publiés ou non, émanant des établissements d'enseignement et de recherche français ou étrangers, des laboratoires publics ou privés. 


\title{
Gradient or statistical copolymers by batch nitroxide mediated polymerization: effect of styrene/methyl acrylate feed $\dagger$
}

\author{
Khaled Karaky, ${ }^{a}$ Eve Péré,${ }^{b}$ Claude Pouchan, ${ }^{b}$ Hélène Garay, ${ }^{c}$ Abdel Khoukh, ${ }^{a}$ \\ Jeanne François, ${ }^{a}$ Jacques Desbrières ${ }^{a}$ and Laurent Billon*a
}

\begin{abstract}
Monomer reactivity ratios in controlled radical copolymerization of styrene (S) and methyl acrylate (MA) monomers at $120{ }^{\circ} \mathrm{C}$ were determined. The Fineman-Ross method was used to calculate $r_{\mathrm{s}}$ and $r_{\mathrm{MA}}$. Using this method, monomer reactivity ratio values of 0.89 and 0.22 were calculated for styrene and methyl acrylate, respectively. Because of the different reactivity ratios between the two monomers, and according to the molar fractions of two monomers, S/MA statistical or gradient copolymers were synthesized by nitroxide-mediated polymerization. Indeed, for different monomer ratios, the same statistical or gradient copolymers can be obtained by batch nitroxide mediated polymerization. These copolymers have been characterized by ${ }^{1} \mathrm{H}$ nuclear magnetic resonance and size exclusion chromatography, and evolution of the composition has been correlated with the glass transition temperature measured by differential scanning calorimetry. Integrated intensities of the three observed peaks of $\left(-\mathrm{OCH}_{3}\right)$ group in the ${ }^{1} \mathrm{H}$ NMR spectra were used to determine the MA/MA/MA, MA/MA/S and S/MA/S triad sequences in the copolymers. Specific organization at the air/polymer interface of such copolymers has also been demonstrated by comparison between classical and attenuated total reflection (ATR) Fourier transform infra-red spectra.
\end{abstract}

\section{Introduction}

The use of controlled radical polymerization (CRP) is becoming more and more popular largely because of its mild reaction conditions and the large scope of polymerizable monomers. ${ }^{1}$ CRP is based on the reversible activation/deactivation equilibrium between the active and dormant species $\left(\mathrm{P}_{n}{ }^{\bullet}\right.$ and $\mathrm{P}-\mathrm{X}$ respectively). This equilibrium, shifted towards the dormant species, keeps the instantaneous concentration of the active radicals low, and reduces the proportion of termination reactions. ${ }^{2}$ This technique is able to produce linear homopolymers as well as polymers with more complex architecture, such as block, random, graft and gradient copolymers. It provides access to polymers with controlled molecular weight and narrow molecular weight distributions. ${ }^{3-6}$ CRP involves different mechanisms such as reversible addition-fragmentation

\footnotetext{
$\overline{{ }^{a} \text { Laboratoire de Physico-Chimie des Polymères, (CNRS UMR 5067), }}$ Université de Pau et des Pays de l'Adour, Hélioparc, 2 Avenue du Président Angot, 64053 Pau Cedex, France. E-mail:

laurent.billon@univ-pau.fr.E-mail:khaked.karaky@univ-pau.fr. E-mail:abdel.khoukh@univ-pau.frjeanne.françois@univpau.frjacques.desbrières@univ-pau.fr

${ }^{b}$ Laboratoire de Chimie Théorique et Physico-chimie Moléculaire, (CNRS UMR 5624), Université de Pau et des Pays de l'Adour, Hélioparc, 2 Avenue du Président Angot, 64053 Pau Cedex, France. E-mail: eve.pere@univ-pau.fr.E-mail: claude.pouchan@univ-pau.fr ${ }^{c}$ Centre des Matériaux de Grande Diffusion, Ecole des Mines d'Alès, Hélioparc, 2 Avenue du Président Angot, 64053 Pau Cedex, France. E-mail: Helene.Garay@ema.fr
}

chain transfer (RAFT), atom transfer radical polymerization (ATRP), and nitroxide-mediated radical polymerization (NMP). ${ }^{7}$ All of these synthetic pathways provide major control of the monomer insertion in the growing polymer chain. Monomer reactivity ratios are important quantitative values to predict the copolymer composition for any starting feed in batch, semi-batch or continuous reactors and to understand the kinetic and mechanistic aspects of copolymerization. Recently, on the basis of the reactivity ratio between the monomers, it has been shown that it is possible to prepare by ATRP a new class of materials, gradient copolymers ${ }^{8}$ (Fig. 1).

Gradient copolymers are copolymers in which the instantaneous composition of the polymer changes continuously from one end of the chain to the other. ${ }^{9-11}$ Two ways can be used to obtain such copolymers.

The first method is based on a controlled addition of one of the monomer during the course of the copolymerization. ${ }^{12}$ It leads to "controlled gradient copolymers". For example Matyjazsewski et al. have synthesized poly(methyl methacrylate-grad-2-(trimethylsilyloxy)ethyl methacrylate), (MMAgrad-HEMA-TMS) by continuous addition of HEMA-TMS during MMA polymerization via ATRP. ${ }^{13}$ Gray et al. have also described the preparation of controlled gradient copolymers styrene/acetoxystyrene and styrene/4-hydroxystyrene respectively via NMP by using TEMPO as counter radical. ${ }^{14}$

In the second method, copolymers are prepared by classical batch copolymerization and a spontaneous gradient in the chain is obtained through the variation of composition due to the large difference between the reactivity ratios of the two monomers. ${ }^{12}$ This technique leads to "spontaneous gradient 


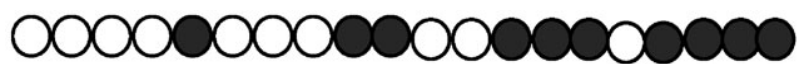

Fig. 1 Structure of gradient copolymer.

copolymers". The syntheses of several types of copolymer: poly(tert-butyl acrylate-grad-octyldecyl methacrylate) ${ }^{15}$ poly(butyl methacrylate-grad-octyldecyl acrylate), ${ }^{15}$ poly(styrene-grad-butyl acrylate) ${ }^{16}$ and poly(styrene-grad-acrylonitrile), have been already described by ATRP. ${ }^{17}$ Moreover, poly( $n$-butyl acrylate-graft-methyl methacrylate) and poly (methyl methacrylate-graft-dimethylsiloxane), synthesized respectively by ATRP and RAFT, showed gradients in side chain density. ${ }^{18}$ Wang et al. have also demonstrated the possibility of obtaining a "spontaneous gradient copolymer" by batch copolymerization from MMA and protected HEMA. ${ }^{19}$

In this type of copolymer, the objective is to control via gradient copolymerization a physical property, density, elasticity, or refractive index, which differs significantly from one homopolymer to another. For example, the thermal property of a polymer sample could be monitored by gradient copolymerization. Farcet et al. have shown that gradient copolymers (styrene $/ n$-butyl acrylate) synthesized by an emulsion process exhibit a single glass transition temperature $T_{\mathrm{g}}{ }^{20}{ }^{20}$ However, two or more distinct $T_{\mathrm{g}}$ can be expected by adjusting the type of distribution or gradient of the monomer units along the chain. In the course of our investigations on the properties of copolymers, we have become interested in the preparation of copolymers based on two monomers leading, when they are used separately, to homopolymers with low and high $T_{\mathrm{g}}$, respectively.

This paper deals with statistical and gradient copolymers of styrene (S) and methyl acrylate (MA), prepared by nitroxide mediated polymerization (NMP) as a function of the monomer feed. The reactivity ratios are calculated using the Fineman-Ross method and the probability distribution for the diad of the comonomer sequence is calculated from the reactivity ratio of the individual monomers $\mathrm{S}$ and MA. This statistical method is used to determine the ratio of three MA centered triads, MA/MA/MA, MA/MA/S and S/MA/S, and at the same time, a ${ }^{1} \mathrm{H}$ NMR study indicated evolution of MA units content in the macromolecular chains. The comparison and the correlation of these statistical and experimental approaches represents the first example described of nitroxide mediated polymerization. The effect of the S/MA initial feed ratio on the batch polymerization was demonstrated. Moreover, the variation of the copolymer $T_{\mathrm{g}}$ is studied by differential scanning calorimetry (DSC) as a function of the composition of monomer units with time. Finally, the chemical organization at the air/polymer interface is investigated by Fourier transform infra-red (FTIR) and attenuated total reflection ATR/FTIR spectroscopy.

\section{Experimental}

\section{Materials}

Styrene (S, 99\%) and methyl acrylate (MA, 99\%) were used as received from Aldrich. The control agent, $N$-tert-butyl-1-

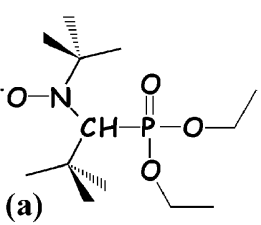

Fig. 2 Chemical structure of SG1 nitroxide (a) and MONAMS alkoxyamine (b).

diethylphosphono-2,2-dimethylpropyl nitroxide (SG1, 85\%) (Fig. 2a), and the alkoxyamine, methyl propionate-SG1 (MONAMS, 95\%) (Fig. 2b), as the initiator, were provided by Atofina Chemicals. All solvents and reagents were used as received without further purification.

\section{Characterization methods}

(a) Nuclear magnetic resonance spectroscopy (NMR). Conversion of styrene and methyl acrylate and copolymer composition were determined by ${ }^{1} \mathrm{H}$ NMR in $\mathrm{CDCl}_{3}$ on a Bruker $400 \mathrm{MHz}$ instrument at $25^{\circ} \mathrm{C}$.

(b) Size exclusion chromatography (SEC). Copolymer molecular weights were determined at $40{ }^{\circ} \mathrm{C}$ using size exclusion chromatography (SEC). Characterizations were performed using a 2690 Waters Alliance System with THF as eluent at a rate of $1 \mathrm{~mL} \min ^{-1}$. The chromatographic device was equipped with four Styragel columns $\operatorname{HR} 0.5,2,4$ and 6 working in series at $40{ }^{\circ} \mathrm{C}$, a 2410 refractive index detector and a 996 Waters Photodiode array detector. A calibration curve established with low polydispersity polystyrene standards was used with toluene as an internal standard for the system.

(c) Differential scanning calorimetry (DSC). Glass transition temperatures $T_{\mathrm{g}}$ were measured using a differential scanning calorimeter, TA series-Q100. Samples $(\sim 5 \mathrm{mg})$ were weighed and scanned at 20 degrees $\min ^{-1}$ at $150{ }^{\circ} \mathrm{C}$ under dry nitrogen $\left(50 \mathrm{ml} \mathrm{min}^{-1}\right)$. The reported values of $T_{\mathrm{g}}$ were determined from the second heating run and were taken as the middle point of the $\Delta H / \mathrm{d} t$ step in the DSC spectra.

(d) Fourier transform infrared (FTIR). The Fourier transform infrared (FTIR) spectra were recorded using a Bruker IFS $66 / \mathrm{S}$ spectrometer at a resolution of $4 \mathrm{~cm}^{-1}$ in absorption mode. 200 scans were accumulated.

(e) Attenuated total reflection-Fourier transform infrared (ATR-FTIR). The spectrometer was a Nicolet Nexus spectrometer. The ATR accessory was a Spectra Tech accessory with a crystal of $\mathrm{ZnSe}\left(n_{1}=2.4\right)$ and an incidence angle of $45^{\circ}$. The spectra were recorded with 200 scans with a resolution of $4 \mathrm{~cm}^{-1}$. According to eqn (1),

$$
d=\lambda /\left[2 \pi n_{1}\left[\sin ^{2} \theta-\left(n_{2} / n_{1}\right)^{2}\right]^{0.5}\right]
$$

where $\lambda$ is the wavelength in $\mathrm{cm}, n_{1}$ and $n_{2}$ are the refractive indices of the crystal and of the polymer respectively, and $\theta$ is the incidence angle of the crystal, the order of the penetration depth $d$ varies from 3.10 to $0.61 \mu \mathrm{m}$ for wavenumber $\nu$ of 650 and $3300 \mathrm{~cm}^{-1}$, respectively (with $\nu=1 / \lambda$ and $n_{2}=1.5$ ). 


\section{Reactivity ratios of styrene and methyl acrylate}

The reactivity ratios were determined by performing a thermal polymerization at $120{ }^{\circ} \mathrm{C}$ of several S/MA mixtures by varying each time the molar fractions of the two monomers. The copolymer-monomers mixtures were analyzed by ${ }^{1} \mathrm{H}$ NMR. The determination of the conversion for each polymer gave the amounts of styrene and methyl acrylate monomers in the copolymer. Monomer reactivity ratios in controlled radical copolymerization of styrene and methyl acrylate were determined for conversion $<30 \%$. The polymer-monomers mixture was dissolved in toluene and precipitated in ethanol. The copolymer was then filtered and all traces of solvent were removed overnight by vacuum drying at room temperature in an oven.

\section{Batch copolymerization of S and MA by NMP}

Nitroxide mediated polymerization of $\mathrm{S}$ and MA was performed in bulk at $120^{\circ} \mathrm{C}$ in the presence of MONAMS as the initiator with a slight excess of counter radical nitroxide SG1. In a round flask, we introduced $N$-tert-butyl-1-diethylphosphono-2,2-dimethylpropyl nitroxide (SG1, $0.01 \mathrm{~g}, 0.034$ mmol), methyl propionate-SG1 (MONAMS, $0.23 \mathrm{~g}, 0.603$ $\mathrm{mmol}$ ), styrene (5.124 g, $49 \mathrm{mmol})$ and methyl acrylate (20.43 g, $237.5 \mathrm{mmol})$. From these experimental values, classical ratios were calculated $[\mathrm{S}-\mathrm{MA}] /[\mathrm{MONAMS}] \approx 475$; $[\mathrm{SG} 1] /[\mathrm{MONAMS}] \approx 0.056$ and $[\mathrm{S}] /[\mathrm{MA}]=17 / 83$. This mixture was stirred until all the initiator was dissolved completely and the solution was degassed by nitrogen bubbling for $30 \mathrm{~min}$ at room temperature. Afterwards, the flask was placed in a thermostatted oil bath at $120{ }^{\circ} \mathrm{C}$. During this time, the viscosity of the solution increased substantially. Samples of the copolymerization mixture were withdrawn at periodic intervals, and conversion was determined by ${ }^{1} \mathrm{H}$ NMR spectroscopy while molecular weights were determined by SEC. The reaction was stopped after $400 \mathrm{~min}$ by cooling the flask to room temperature and exposing the reaction mixture to air. The polymer solution was dissolved in toluene $(15 \mathrm{ml})$, precipitated in ethanol $(500 \mathrm{ml})$, and the resulting solid was isolated by vacuum filtration and dried overnight under vacuum. Monomer conversion was found to be $98 \% \mathrm{~S}$ and $68 \%$ MA ( ${ }^{1} \mathrm{H}$ NMR). The average molecular weight and molecular weight distribution were measured using SEC, $M_{\mathrm{n}}=39200 \mathrm{~g}$ mole, $I_{\mathrm{p}}=1.12$.

For other copolymers, the experimental conditions were the same except for the initial quantities of styrene and methyl acrylate. Experimental conditions are summarized in Table 1.

For the other two sets, the initial S/MA ratios were 40/60 and 80/20 leading to monomer conversions of $90 / 76$ and 70/64, respectively. At the same time, the number average molecular

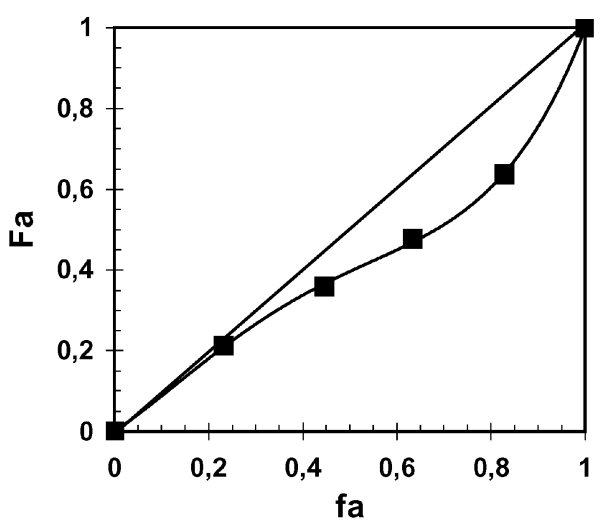

Fig. 3 Influence of the MA fraction in the monomer feed $\left(f_{\mathrm{a}}\right)$ on the MA fraction in the copolymer formed $\left(F_{\mathrm{a}}\right)$.

weight $\left(M_{\mathrm{n}}\right)$ and the polydispersity index $\left(I_{\mathrm{p}}\right)$ were determined as $M_{\mathrm{n}}=41100 \mathrm{~g} \mathrm{~mol}^{-1}\left(I_{\mathrm{p}}=1.14\right)$ and $M_{\mathrm{n}}=39000 \mathrm{~g} \mathrm{~mol}^{-1}$ $\left(I_{\mathrm{p}}=1.15\right)$, respectively.

\section{Results and discussion}

\section{Reactivity parameters}

First of all, the reactivity of MA seems to be lower than that of $\mathrm{S}$ in the feed mixture. Indeed, Fig. 3 shows that the instantaneous molar content of MA in the feed $f_{\mathrm{a}}$ is higher than the molar fraction of MA in the copolymer $F_{\mathrm{a}}$, at least for $f_{\mathrm{a}}>$ 0.2 . This indicates a large difference in reactivity between the $\mathrm{MA}$ and $\mathrm{S}$ monomers.

By using the method of Fineman and Ross usually done with very low conversion, ${ }^{21 a}$ the reactivity ratios were determined: $r_{\mathrm{S}}=0.89$ and $r_{\mathrm{MA}}=0.22$. Here, the determination of the reactivity ratios is only possible because of the control of the polymerization and the linearity of the evolution of the conversion (see Kinetics of batch copolymerization; next section). Moreover, the same values were obtained with the modified Kelen-Tüdos equation. ${ }^{21 b}$

These values are in good agreement with the values obtained in bulk at $25^{\circ} \mathrm{C}$ by other methods ${ }^{22}$ and reported in Table 2. The reactivity ratios are roughly equal despite the differences in the free radical method used and in temperature (Table 2).

Moreover, due to the superposition of the experimental and theoretical points up to $f_{\mathrm{a}}=0.4$ in Fig. 3 , we can deduce that $\mathrm{S}$ and MA tend to form macromolecular chains with the same composition as the initial feed. The curve $F_{\mathrm{a}}=\mathrm{f}\left(f_{\mathrm{a}}\right)$ must be a sigmoid and cross the ideal line (azeotropic point $F_{\mathrm{a}}=f_{\mathrm{a}}$ ) for a value of $f_{\mathrm{a}}=0.12\left(f_{\mathrm{a}}=\left(1-r_{\mathrm{MA}}\right) /\left(2-\left(r_{\mathrm{S}}+r_{\mathrm{MA}}\right)\right)\right)$. This is consistent with Fig. 3, which shows that the comonomer mixture $f_{\mathrm{a}}=0.2$ is almost azeotropic $\left(F_{\mathrm{a}}=f_{\mathrm{a}}\right)$, while for

Table 1 Experimental conditions for different synthesized copolymers

\begin{tabular}{|c|c|c|c|c|c|c|c|c|c|}
\hline \multirow{2}{*}{$\begin{array}{l}\text { S/MA } \\
(\mathrm{mol} \%)\end{array}$} & \multirow{2}{*}{$\begin{array}{l}\text { Styrene/ } \\
\text { mol }\end{array}$} & \multirow{2}{*}{$\begin{array}{l}\text { Methyl } \\
\text { acrylate/mole }\end{array}$} & \multirow{2}{*}{$\begin{array}{l}\text { MONAMS/ } \\
\text { mol } \times 10^{-4}\end{array}$} & \multirow{2}{*}{$\begin{array}{l}{[\mathrm{SG} 1] /} \\
{[\mathrm{MONAMS}]}\end{array}$} & \multicolumn{2}{|c|}{ Monomer conversion } & \multirow{2}{*}{$\begin{array}{l}\text { Time/ } \\
\text { min }\end{array}$} & \multirow[b]{2}{*}{$M_{\mathrm{n}}(\mathrm{SEC})$} & \multirow[b]{2}{*}{$I_{\mathrm{p}}$} \\
\hline & & & & & $\% \mathrm{~S}$ & $\% \mathrm{MA}$ & & & \\
\hline $17 / 83$ & 0.049 & 0.237 & 6.036 & 0.056 & 98 & 68 & 400 & 39200 & 1.12 \\
\hline $40 / 60$ & 0.096 & 0.147 & 5.084 & 0.056 & 90 & 76 & 280 & 41100 & 1.14 \\
\hline $80 / 20$ & 0.16 & 0.04 & 4.2 & 0.056 & 70 & 64 & 260 & 39000 & 1.15 \\
\hline
\end{tabular}


Table 2 Reactivity ratios of $\mathrm{S}$ and MA calculated by different methods

\begin{tabular}{lll}
\hline Method & $r_{\mathrm{s}}$ & $r_{\text {MA }}$ \\
\hline YBR $^{22}$ & 0.85 & 0.21 \\
Kelen-Tudos $^{22}$ & 0.84 & 0.21 \\
Tidwell-Mortimer $^{22}$ & 0.84 & 0.21 \\
Kelen-Tudos $^{a}$ & 0.89 & 0.22 \\
Fineman-Ross $^{a}$ & 0.89 & 0.22 \\
${ }^{a}$ In this work. & & \\
\hline
\end{tabular}

higher fractions of MA in the feed, composition drift should be observed.

\section{Kinetics of batch copolymerization}

The composition gradient of the copolymers can be characterized through the copolymerization kinetics. Conversions of $\mathrm{S}$ and MA as well as $M_{\mathrm{n}}$ and $I_{\mathrm{p}}$ were measured as a function of polymerization time. Some results are given in Fig. 4 and 5. The $\mathrm{S}$ and MA conversions were obtained by ${ }^{1} \mathrm{H}$ NMR versus time for three different initial compositions of the feed, $f_{\mathrm{a}}=0.20,0.60$ and 0.83 .

Fig. 4a shows the evolution of $\ln \left(\left[\mathrm{M}_{0}\right] /[\mathrm{M}]\right)$ where $\left[\mathrm{M}_{0}\right]$ and $[\mathrm{M}]$ are the initial and instantaneous molar concentrations of the considered monomer, respectively. The slopes of the straight lines are equal to $K_{\mathrm{p}}\left[\mathrm{M}^{\bullet}\right]$, the product of the polymerization constant $K_{\mathrm{p}}$ of this comonomer multiplied by the number of active centers $\left[\mathrm{M}^{\bullet}\right]$.

At first it is important to observe the same polymerization constants for both comonomers, for the feed composition $f_{\mathrm{a}}=$ 0.20 , which is very close to the azeotropic one, as expected from Fig. 3. This confirms the tendency for S and MA to incorporate in the chain and to form a copolymer without drift composition. However, in the other two cases, $f_{\mathrm{a}}=0.83$ and 0.60 , the polymerization of $\mathrm{S}$ appears to be much faster than that of MA. Then the copolymers obtained with an initial feed fraction of MA higher than $20 \%$ will be characterized by a spontaneous composition gradient.

Fig. 5 shows the SEC results obtained for copolymerization performed with the fraction $f_{\mathrm{a}}=0.83$. A linear increase of $M_{\mathrm{n}}$

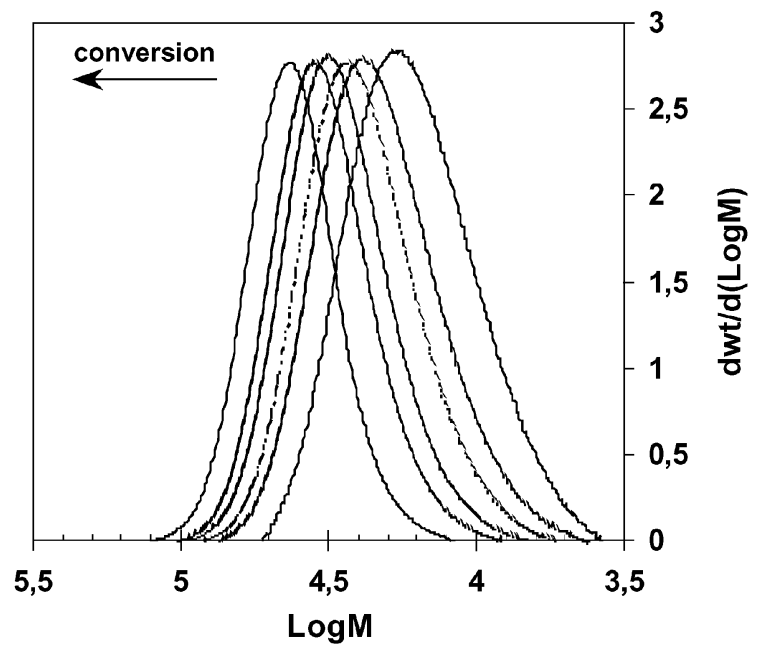

Fig. 5 SEC traces of the samples of poly(S/MA) for fraction $f_{\mathrm{a}}=0.83$ with time.

and a decrease of the peak surface are observed without the appearance of any shoulder in the chromatograms, at high polymerization time. It can be observed that the peaks shift towards higher $M_{\mathrm{n}}$ indicating a controlled polymerization reaction. As shown by Fig. 4b, when the reaction is stopped at $98 \%$ and $64 \% \mathrm{~S}$ and MA conversions, respectively, the $M_{\mathrm{n}}$ is $39200 \mathrm{~g} \mathrm{~mol}^{-1}$ and $I_{\mathrm{p}}$ is 1.12 .

\section{${ }^{1}$ H NMR peak assignment and microstructure of the copolymers (S/MA)}

By changing the monomer ratio, we notice a variation of the speed of consumption between the two monomers. Indeed, with $f_{\mathrm{a}}=0.83$ and 0.60 , we clearly observe that $\mathrm{S}$ is more reactive than MA, with an increase in the quantity of S (Fig. 4a). The probability of obtaining gradient copolymers between these two monomers decreases when the $\mathrm{S}$ fraction is increased in the feed of the batch NMP.

For the last copolymer synthesized with a fraction $f_{\mathrm{a}}=$ 0.20 , it is clear that this copolymer does not exhibit a
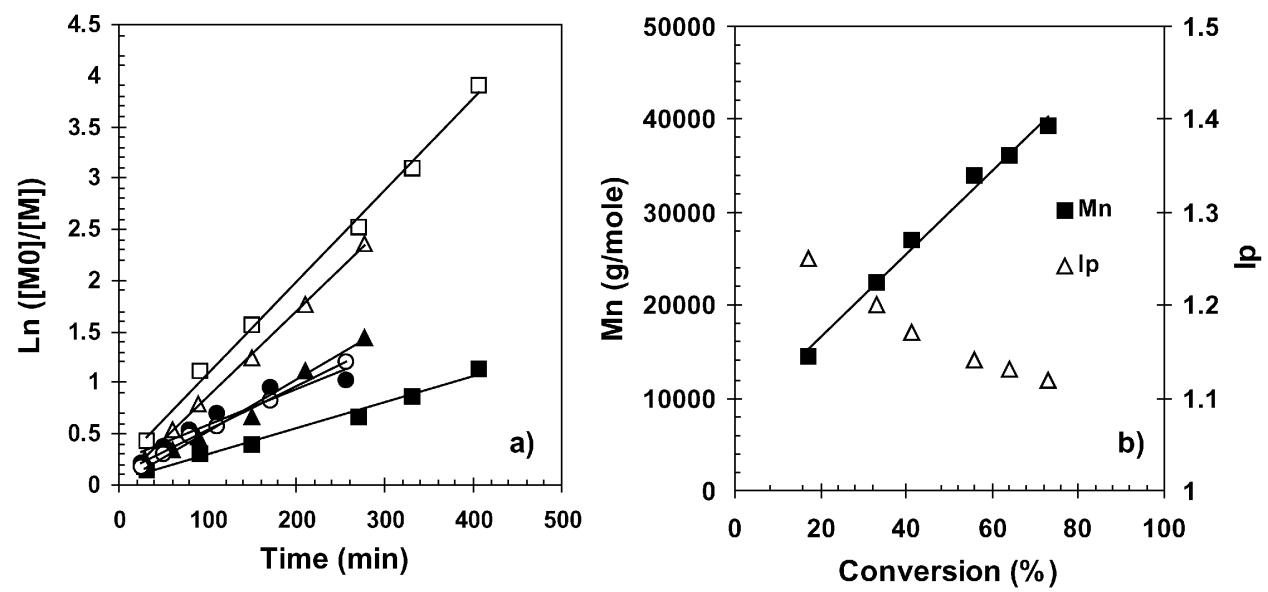

Fig. 4 (a) Variation of the $\ln [\mathrm{M}]_{0} /[\mathrm{M}]$ of styrene $\mathrm{S}$ (open symbols) and methyl acrylate MA (full symbols) versus time (for fraction $f_{\mathrm{a}}=0.60$ $(\triangle / \mathbf{\Delta}) ; 0.2(\bigcirc / \bigcirc)$ and $0.83(\square / \mathbf{\square}))$ and (b) evolution of macromolecular dimensions of fraction $f_{\mathrm{a}}=0.83$ as a function of conversion in nitroxide mediated batch copolymerization at $120{ }^{\circ} \mathrm{C}$. 
Aromatics
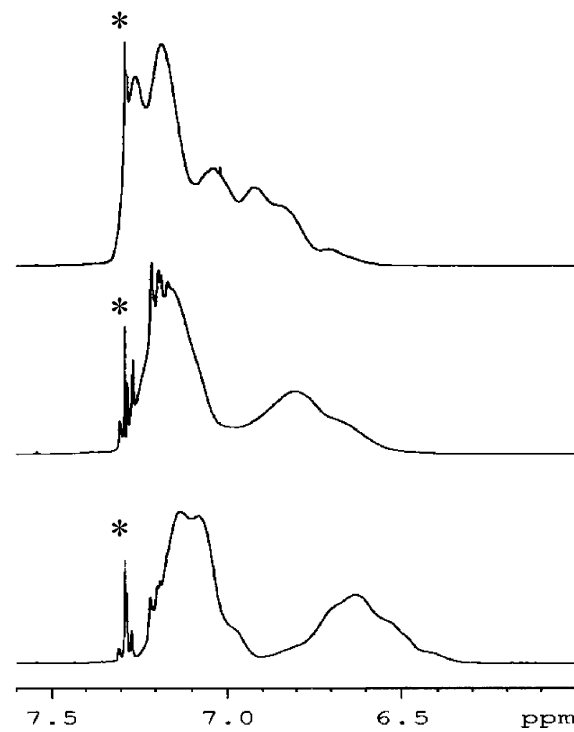

$\mathrm{OCH}_{3}$
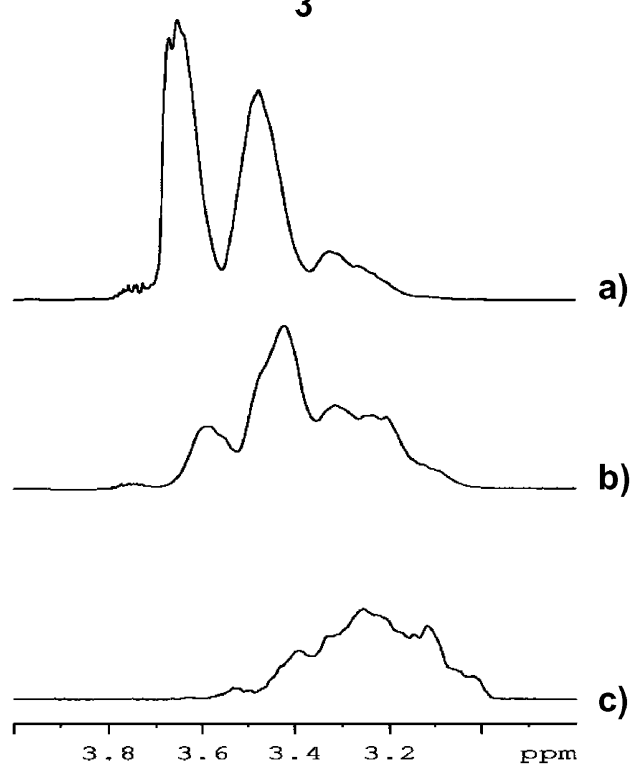

Fig. $6 \quad{ }^{1} \mathrm{H}$ NMR spectra of poly(S/MA) for different monomer feed fractions $f_{\mathrm{a}}=0.83$ (a), 0.60 (b), 0.20 (c) $(*$ indicates the presence of solvent $\mathrm{CHCl}_{3}$ ).

composition gradient which is quite consistent with result of Fig. 4a. The consumption rates of the two monomers being similar, no monomer has the advantage of incorporating itself more quickly than the other, which leads to a statistical copolymer with azeotropic composition.

The ${ }^{1} \mathrm{H}$ NMR spectra of different S/MA copolymers show the effect of feed composition (Fig. 6). The evolution of the peaks is due to 1) the copolymer composition, 2) the distribution of the monomer units and 3 ) the polymer tacticity. Indeed, for the two regions explored by ${ }^{1} \mathrm{H}$ NMR, significant differences are observed. In the $\mathrm{OCH}_{3}$ region (MA), the increase of the MA amount is associated with the appearance of two new peaks at higher chemical shift. In the aromatic area, the peaks are shifted in a similar manner.

Moreover for the copolymer with $f_{\mathrm{a}}=0.83$, three distinct peaks in the range 3.1 to $3.8 \mathrm{ppm}$ are observed. In Fig. 7, we can clearly note an increase in the intensity of peak I with polymerization time from the kinetic data and by comparison with the chemical shift of a PMA homopolymer. Moreover, at the same time, one notes that the intensities of peaks II and III decrease gradually, which can be associated with a reduction in the incorporation of $\mathrm{S}$ units with time.

From these observations and results, peaks I, II and III could be assigned to the $\mathrm{MA} / \mathrm{MA} / \mathrm{MA}, \mathrm{MA} / \mathrm{MA} / \mathrm{S}$ and $\mathrm{S} / \mathrm{MA} / \mathrm{S}$ triad respectively.

The probability distribution for the diad of the comonomer sequence can also be calculated from the reactivity ratio of individual monomers according to Ito and Yamashita. ${ }^{23}$ This method can be used to determine the ratio of three centered triads as previously described for different couples of comonomers. ${ }^{23-26}$

$$
P_{\mathrm{MM}}=\left(r_{\mathrm{M}} \cdot x\right) /\left(1+r_{\mathrm{M}} \cdot x\right) ; P_{\mathrm{MS}}=1 /\left(1+r_{\mathrm{M}} \cdot x\right)
$$

One can calculate the instantaneous triad distribution with

$$
F_{\mathrm{MMM}}=\left(P_{\mathrm{MM}}\right)^{2} ; F_{\mathrm{MMS}}=2 \cdot P_{\mathrm{MM}} \cdot P_{\mathrm{MS}} ; F_{\mathrm{SMS}}=\left(P_{\mathrm{MS}}\right)^{2}
$$

In order to obtain the average triad distribution which varies with time, one has to integrate $F_{\text {MMM }}, F_{\text {MMS }}$ and $F_{\text {SMS }}$ between $x_{0}$ and each time value $x$, determined from the data of Fig. 4. This approach has been recently used by Madruga et $a l .{ }^{27}$ for nitroxide-mediated free-radical copolymerization of styrene and butyl acrylate. Here, the main difference is due to the correlation of the average values $F_{\mathrm{MMM}}, F_{\mathrm{MMS}}$ and $F_{\mathrm{SMS}}$ directly comparable with NMR results. To our knowledge,

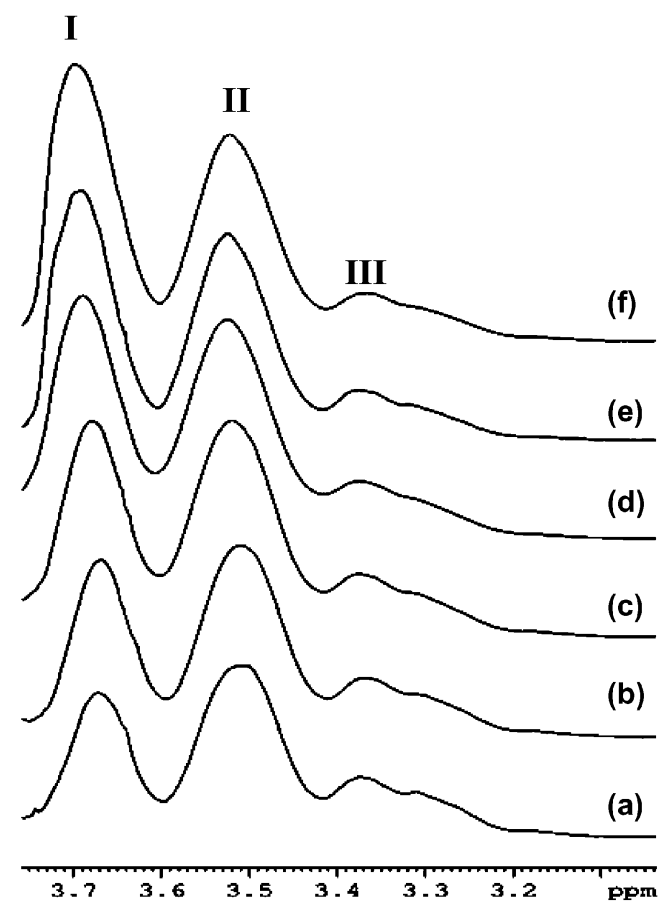

Fig. 7 Evolution of triad distribution with time by ${ }^{1} \mathrm{H}$ NMR spectroscopy in the $\left(-\mathrm{OCH}_{3}\right)$ region (fraction $f_{\mathrm{a}}=0.83$ ). 


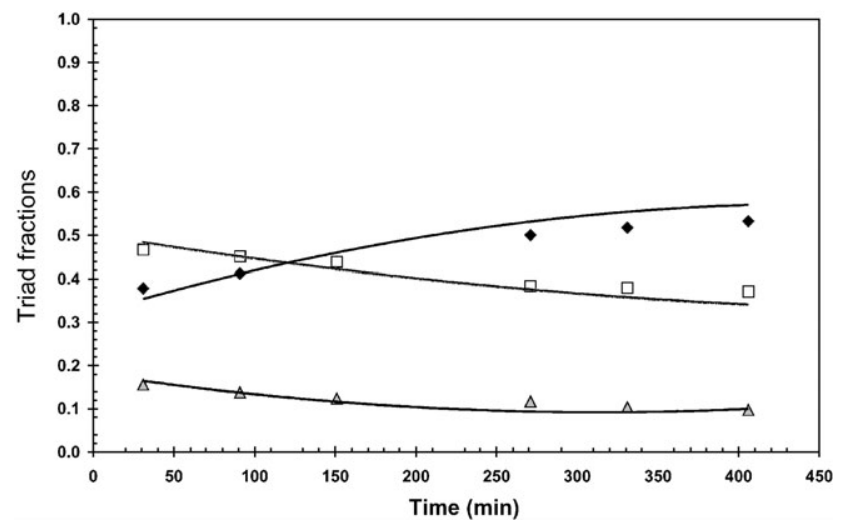

Fig. 8 (a) Calculated (lines) and (b) ${ }^{1} \mathrm{H}$ NMR experimental (symbols) variations of triad fractions with time for fraction $f_{\mathrm{a}}=0.83(\checkmark \mathrm{MA} /$ $\mathrm{MA} / \mathrm{MA} ; \square \mathrm{MA} / \mathrm{MA} / \mathrm{S} ; \triangle \mathrm{S} / \mathrm{MA} / \mathrm{S}$ : MA centered triads).

this work represents for the first time the calculated/experimental average triad distribution relationship. The values of $F_{\mathrm{MMM}}, F_{\mathrm{MMS}}$ and $F_{\mathrm{SMS}}$ are compared in Fig. 8 with those obtained from the ${ }^{1} \mathrm{H}$ NMR spectra and by using the peak assignments indicated above, for the initial feed fraction $f_{\mathrm{a}}=0.83$.

One can consider the agreement between the two sets of values as very good, if one takes into account the characteristics of ${ }^{1} \mathrm{H}$ NMR spectra reproduced in Fig. 7. The several peaks assigned to the various triad are not well separated and are rather broad. Peak III assigned to the S/MA/S triad exhibits a shoulder at $3.3 \mathrm{ppm}$. In a more complete and detailed work, it may be useful to consider not only the composition of the triad but also the tacticity of the triad. Nevertheless, since the agreement between the calculated and experimental average fractions of the triad is good, one can consider that Fig. 8 well reflects the evolution of the composition from one end to the other end of the chain. This behaviour can be associated with the creation of gradient copolymers in the macromolecular chains with the polymerization process.

On the other hand, we have carried out the same study for the two other series of copolymers prepared from the feeds $f_{\mathrm{a}}=0.20$ and 0.60 (see ESI $\dagger$ ). In the same range of chemical shifts in the ${ }^{1} \mathrm{H}$ NMR spectra, no change are observed versus reaction time, in the first case. This result is quite normal, since this comonomer mixture was already shown to be an azeotropic one. In the intermediate case $\left(f_{\mathrm{a}}=0.60\right)$, small variations of $F_{\mathrm{MMM}}, F_{\mathrm{MMS}}$ and $F_{\mathrm{SMS}}$ are observed with the conversion time. As for fraction $f_{\mathrm{a}}=0.83$, this evolution is in good agreement with the results of calculations.

Moreover, some other confirmations can be obtained from the ${ }^{1} \mathrm{H}$ NMR study. Indeed in Fig. 9, it can be clearly seen that for high initial molar fractions of styrene $(80 \%)$, the cumulative fraction of styrene remains almost constant during the polymerization reaction, which shows that the distribution of the monomer units of styrene in the polymer does not change along the macromolecular skeleton.

This behaviour can be directly anticipated from Fig. 3 and 4a. Here, it is important to note that the nitroxide-mediated free-radical copolymerization of styrene and butyl acrylate has

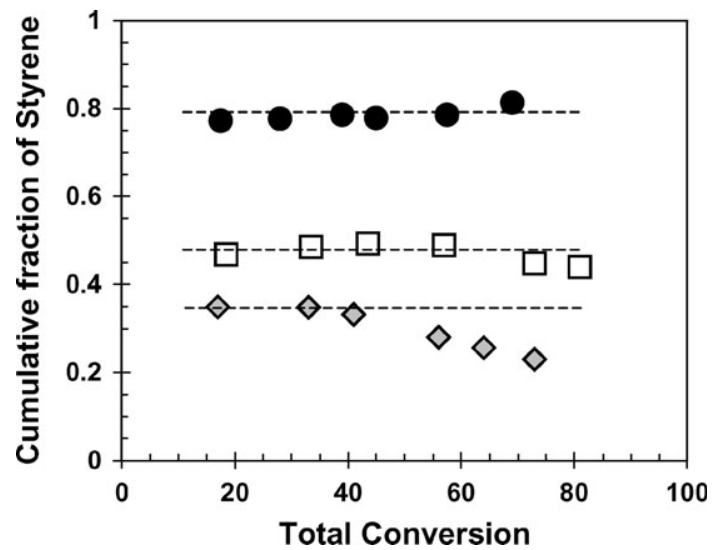

Fig. 9 Plots of S content in poly(S/MA) as a function of conversion $(\diamond 17 \% ; \square 40 \%$ and $\bullet 80 \%$ of styrene).

been reported by Madruga et al. ${ }^{27}$ and same behaviour has been observed. But in their study, the authors never mentioned the possibility to induce a gradient copolymer structure by modification of the initial feed of the batch copolymerization.

Indeed, with the reduction of $\mathrm{S}$ in the initial monomer feed composition, we observe a reduction of the $\mathrm{S}$ instantaneous fraction according to the total conversion. This behaviour is better noticed in the last case of $17 \%$, where the styrene conversion decreases as function of total conversion, than for $40 \%$ of $\mathrm{S}$ where a slight inflexion occurs for $80 \%$ of conversion. For the initial feed fraction $f_{\mathrm{a}}=0.83$, the composition of the copolymer changed clearly and gradually from the early stages of copolymerization with the increase of the monomer conversions. This behaviour is pronounced and suggests that, through this process, the gradient copolymer of S/MA can be obtained and controlled by NMP.

\section{Thermal property of the S/MA gradient copolymer}

Another technique of characterization which confirms the gradient structure is differential scanning calorimetry (DSC). A kinetic study was carried out by DSC on the polymer obtained from the fraction $f_{\mathrm{a}}=0.83$. For this copolymer only one glass transition $T_{\mathrm{g}}$ has been detected. Fig. 10 shows the

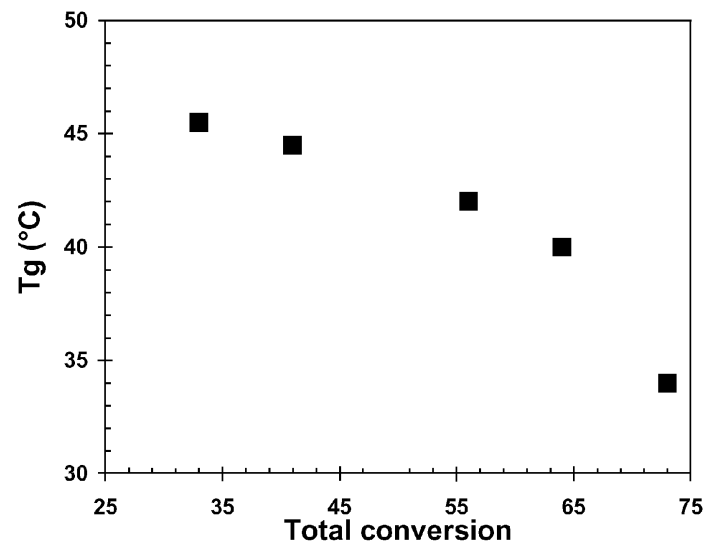

Fig. 10 Evolution of $T_{\mathrm{g}}$ of copolymer as a function of conversion fraction $\left.f_{\mathrm{a}}=0.83\right)$. 
evolution of $T_{\mathrm{g}}$ versus the total monomer conversion from 45.5 to $34{ }^{\circ} \mathrm{C}$.

This $T_{\mathrm{g}}$ evolution corresponds to the variation of the chemical composition in the macromolecular chains. The low $T_{\mathrm{g}}$ obtained in this case $\left(34{ }^{\circ} \mathrm{C}\right)$, was between the $T_{\mathrm{g}}$ of PS $\left(\approx 100{ }^{\circ} \mathrm{C}\right)$ and that of PMA $\left(\approx 10{ }^{\circ} \mathrm{C}\right)$. It is clear that this $T_{\mathrm{g}}$ decreases as a function of conversion with the cumulative fraction of $\mathrm{S}$ with time as previously described in Fig. 9. This diminution returns to the increase in the incorporation of MA units in the copolymer, with the consequence of a higher consumption of MA than S.

It is necessary to note that for the copolymer obtained from fraction $f_{\mathrm{a}}=0.20$, the $T_{\mathrm{g}}$ values are constant and equal to $80{ }^{\circ} \mathrm{C}$. At the same time, for the copolymer from fraction $f_{\mathrm{a}}=0.60$, such a phenomenon is observed with an average value of $T_{\mathrm{g}}$ around $49{ }^{\circ} \mathrm{C}$. These behaviours confirm the statistical process of the macromolecular elaboration as also described in Fig. 9.

\section{Surface analysis by ATR-FTIR}

In addition, a technique based on attenuated total reflectance Fourier transform infrared spectroscopy was used to study the chemical surfaces of these polymers to show an effective surface segregation of copolymer gradient. This study was performed on a plate of $3 \mathrm{~mm}$ thickness obtained under vacuum after a thermal treatment of 3 hours at $80{ }^{\circ} \mathrm{C}$ and a slow temperature decrease over 5 hours to room temperature.

In Fig. 11, the ATR-FTIR (a) and FTIR (b) spectra show the presence of peaks $(\mathrm{C}=\mathrm{O})$ around $1730 \mathrm{~cm}^{-1}$ of methyl acrylate as well as peaks $(\mathrm{C}=\mathrm{C})$ of styrene around $1600 \mathrm{~cm}^{-1}$.

By comparison between the $(\mathrm{C}=\mathrm{O}) /(\mathrm{C}=\mathrm{C})$ intensity ratios, values of $\approx 5$ and 15 are obtained by FTIR and FTIR-ATR, respectively. We note in the second case an important increase of the peak intensity of $(\mathrm{C}=\mathrm{O})$, which is three times higher than in the case of FTIR. Indeed, the units of methyl acrylate are formed by polar groups, and it seems that they tend to migrate towards the surface. In this area of the spectrum, the penetration depth is around $1.10 \mu \mathrm{m}$ (see eqn (1) in Experimental section). Moreover, similar behaviour is observed in the $\mathrm{C}-\mathrm{H}$ vibration area between 2800 and $3100 \mathrm{~cm}^{-1}$. In this case we observe a decrease of the peak intensity of the aromatic groups of the styrene units compared to the aliphatic groups (penetration depth of $0.63 \mu \mathrm{m}$ ) with the same order of

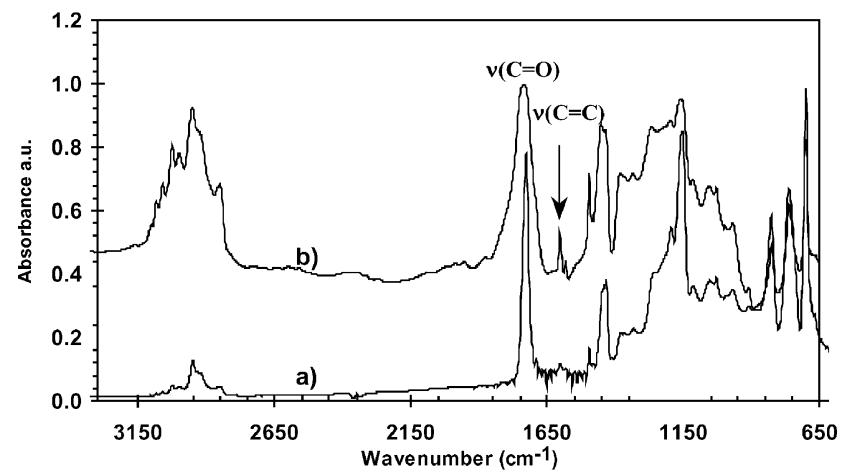

Fig. 11 ATR-FTIR (a) and FTIR (b) spectra for the copolymer with fraction $f_{\mathrm{a}}=0.83$. magnitude as previously determined for the $(C=O) /(C=C)$ intensity ratios. We can also observe that the peak of the carbonyl function obtained by FTIR is broader than that observed by ATR-FTIR, characteristic of environment and mobility changes of MA in the extreme surface.

These two similar observations could be correlated with a variation of the composition near the surface in such a gradient copolymer. This chemical organization shows that the polymer chains richer in MA than in S at one of its ends could organize the surface. This approach has to be confirmed and the study of extreme surface (X-ray photo-electronic spectroscopy, ellipsometry, atomic force microscopy) and bulk (small angle neutron scattering) analysis are under way on such gradient copolymers.

\section{Conclusion}

Well-defined gradient copolymers from styrene and methyl acrylate monomers were synthesized using NMP. These gradients are prepared by batch copolymerization because of the different reactivity between the two monomers. SEC analysis confirmed that the linear gradient copolymers were made in a controlled manner, as demonstrated by growth of $M_{\mathrm{n}}$ and decrease of $I_{\mathrm{p}}$ with conversion. The DSC analyses show that these materials exhibited one $T_{\mathrm{g}}$ which decreases with the increase of the quantity of MA in the copolymers. Finally, the ${ }^{1} \mathrm{H}$ NMR study shows that triad MA-MA-MA increases according to the time of polymerisation for $\mathrm{S}=17 \%$, which confirms thereafter the gradient in composition of the copolymers. However, the batch copolymerization processes depend strongly on the reactivity ratios of the given monomer pair, which could be a limit in the use of this technique. To avoid this aspect, we will present in a forthcoming paper the possibility to use a semi-batch nitroxide mediated copolymerization method to synthesize gradient copolymers in order to design materials.

\section{Acknowledgements}

The authors gratefully acknowledge the financial support from: FANADT, FEDER, Association "2PSM" and of its director P. Maury for his support and motivation. We would like to thank P. Iratcabal for NMR discussions.

\section{References}

1 K. Matyjazsewski, Controlled Radical Polymerization, American Chemical Society, Washington DC, 2000.

2 D. Bertin, M. Destarac and B. Boutevin, in Polymers and surfaces. A versatile combination, ed. H. Hommel, Research Signpost, Trivandrun, India, 1998, p. 47.

3 S. S. Wang and K. Matyjazsewski, J. Am. Chem. Soc., 1995, 117, 5614.

4 M. Kato, M. Kamigaito, M. Sawamato and T. Higashimura, Macromolecules, 1995, 28, 1721.

5 M. K. Georges, R. P. N. Veregin, P. M. Kazmaier and G. K. Hamer, Macromolecules, 1993, 26, 2987.

6 J. Chiefari, Y. K. Chong, F. Ercole, J. Krstina, J. Jeffery, T. P. T. Le, R. T. A. Mayadunne, G. F. Meijs, C. L. Moad, G. Moad, E. Rizzardo and S. H. Thang, Macromolecules, 1998, 31, 5559.

7 Handbook of Radical Polymerization, ed. K. Matyjazsewski and T. M. Davis, John Wiley \& Sons, Hoboken, NJ, 2002.

8 K. Matyjazsewski, Polym. Adv. Technol., 1997, 8, 244. 
9 T. Pakula and K. Matyjazsewski, Macromol. Theory Simul., 1996, $\mathbf{5}, 987$.

10 D. Greszta and K. Matyjazsewski, Polym. Prepr. (Am. Chem. Soc., Div. Polym. Chem.), 1996, 37, 569.

11 K. Matyjazsewski, M. J. Ziegler, S. V. Arehart, D. Greszta and T. Pakula, J. Phys. Org. Chem., 2000, 13, 775.

12 J. Z. Michael and K. Matyjazsewski, Macromolecules, 2001, 34, 415.

13 G. B. Hang, D. David, K. Matyjazsewski, D. S. Marcelo and S. S. Sergei, Macromolecules, 2002, 5, 3387.

14 M. K. Gray, H. Zhou, S. T. Nguyen and J. M. Torkelson, Macromolecules, 2004, 37, 5586.

15 Q. Shuhui, S. Jocelyn, P. Jeffrey, J. Shijun, K. Tomas and K. Matyjazsewski, Macromolecules, 2003, 36, 8969.

16 S. Arehart, D. Greszta and K. Matyjazsewski, Polym. Prepr. (Am. Chem. Soc., Div. Polym. Chem.), 1997, 38, 705.

17 D. Greszta, K. Matyjazsewski and T. Pakula, Polym. Prepr. (Am. Chem. Soc., Div. Polym. Chem.), 1997, 38, 709.
18 K. Matyjazsewski and H. G. Börner, Macromol. Symp., 2002, 1, 177.

19 P. Liu, J. Hu and C. Wang, Polym. Int., 2004, 53, 136.

20 C. Farcet, B. Charleux and R. Pirri, Macromol. Symp., 2002, 182, 249.

21 (a) M. Fineman and S. D. Ross, J. Polym. Sci., 1949, 5, 259; (b) T. Kelen, F. Tüdos, B. Turcsanyi and J. P. Kennedy, J. Polym. Sci., Polym. Chem. Ed., 1977, 15, 3047.

22 X. Xu, X. Ge, Z. Zhang and M. Zhang, Polymer, 1998, 22, 5321.

23 K. Ito and Y. Yamashita, J. Polym. Sci., Part A3, 1965, 2165.

24 A. S. Brar and C. V. V. Satyanarayana, Polymer, 1992, 24, 879.

25 M. F. LIauro-Darricades, C. Pichot, J. Guillot, G. L. Rios, E. M. A. Cruz and C. C. Guzman, Polymer, 1986, 27, 889.

26 N. D. Truong, J. C. Galin, J. Francois and Q. T. Phan, Polymer, 1986, 27, 467.

27 R. Cuervo-Rodriguez, V. Bordege, M. C. Fernandez-Monreal, M. Fernandez-Garcia and E. Madruga, J. Polym. Sci., 2004, 42, 4168. 